\title{
Carbon emission control measures
}

\author{
L. U. Grema ${ }^{1}$, A. B. Abubakar ${ }^{1}$, O. O. Obiukwu ${ }^{2}$ \\ ${ }^{1}$ Department of Mechanical Engineering, Ramat Polytechnic, P.M.B. 1017 Maiduguri, Nigeria \\ ${ }^{2}$ Department of Mechanical Engineering, Federal University of Technology, Owerri, Nigeria
}

\begin{abstract}
This paper seeks to share the experience of the Ultra Low $\mathrm{CO}_{2}$ Steelmaking programme (ULCOS) established in 2002 by a number of EU members on how to cut down $\mathrm{CO}_{2}$ emission by at least $50 \%$ of the present volume of emission. Global environmental challenge today is the issue of climate change resulting in devastating effects such as flooding in many countries of the world. One of the major causes is the $\mathrm{CO}_{2}$ emission from different industries including iron and steel industries. The total global $\mathrm{CO}_{2}$ emission was put at $29 \mathrm{Gt}$ in 2007 and projected to be $37 \mathrm{Gt}$ by the 2020 . Out of this volume the steel industry accounts for 3-4 \% and this call for concern from stakeholders to come up with measures to reduce or control the emission of the green house gas. These measures are necessary considering the growth of the iron and steel industry in the last 50 years. Important items considered include among others carbon emission and recovery, carbon capture and storage and new iron and steel making processes and their potential for $\mathrm{CO}_{2}$ reduction.
\end{abstract}

Keywords: Emission; Ultra Low $\mathrm{CO}_{2}$; Steel Industry; Recovery

\section{INTRODUCTION AND METHODS}

The struggle for civilization and development is part of human existence. This historical development has some challenges including the issues of global warming mainly from industrial emissions which is a major contributor to green house gas (Kawai, 2001; Losif et al, 2013). Although the topic of discussion here is centered on how iron and steel industries take measures to cut down $\mathrm{CO}_{2}$ emissions we must start by giving a background assessment of the magnitude of the problem and its sources. The issue of global warming started since the industrial revolution of the $19^{\text {th }}$ century, and this lead to increase in temperature of the globe (Farla et al, 2013; Chang et al, 2008).

Human activities generate millions of tons of $\mathrm{CO}_{2}$ annually resulting mainly from industrial emissions whose major source of energy is the fossil fuels (Bonenfant et al, 2009; $\mathrm{Xu}$ and Da-qianq, 2010). The demand for iron and steel has increased tremendously in the last few decades (Vladimir, 2006). With output reaching well above 1240Mt as of 2006. (Xu and Da-qianq, 2010). In 2001 Germany alone produced about 52million tons of $\mathrm{CO}_{2}$ from their industrial production. (Katja and Jayant, 2007). The energy consumption and gas emission depends on the production capacity of the industries and the type of technology employed (Katja and Sand, 1998). Production of iron and steel is one of the energy intensive processes (Katja and Sand, 1998; Katja and Jayant, 2007). The energy consumption of the steel industry is estimated to be $18-19$ EJ or $10-15 \%$ of total global industrial requirements. 
The global $\mathrm{CO}_{2}$ emission as at 2007 is around $29 \mathrm{Gt}$ and is expected to rise by $21 \%$ in 2020.(Xu and Da-qianq, 2010). The steel industries contribute $7 \%$ of global $\mathrm{CO}_{2}$ emission (Vladimir, 2006).

The production routes determine the amount of $\mathrm{CO}_{2}$ emissions because of the differences in the raw materials used and the energy inputs (katja and Jayant, 2007).To protect the environment a high priority is given in the $21^{\text {st }}$ century in that all industrial activities must be done with environmental consciousness (Kawai, 2001)., and that is the more reason why most countries involved in iron and steel productions have different internal environmental laws to tackle the problem of global warming and environmental issues. In countries like France emission control measures include taxing companies for their emissions and some legislation are in place mandating companies to include continuous monitoring equipments of pollutants emitted from the industries, (Lonescu and Candau, 2007).

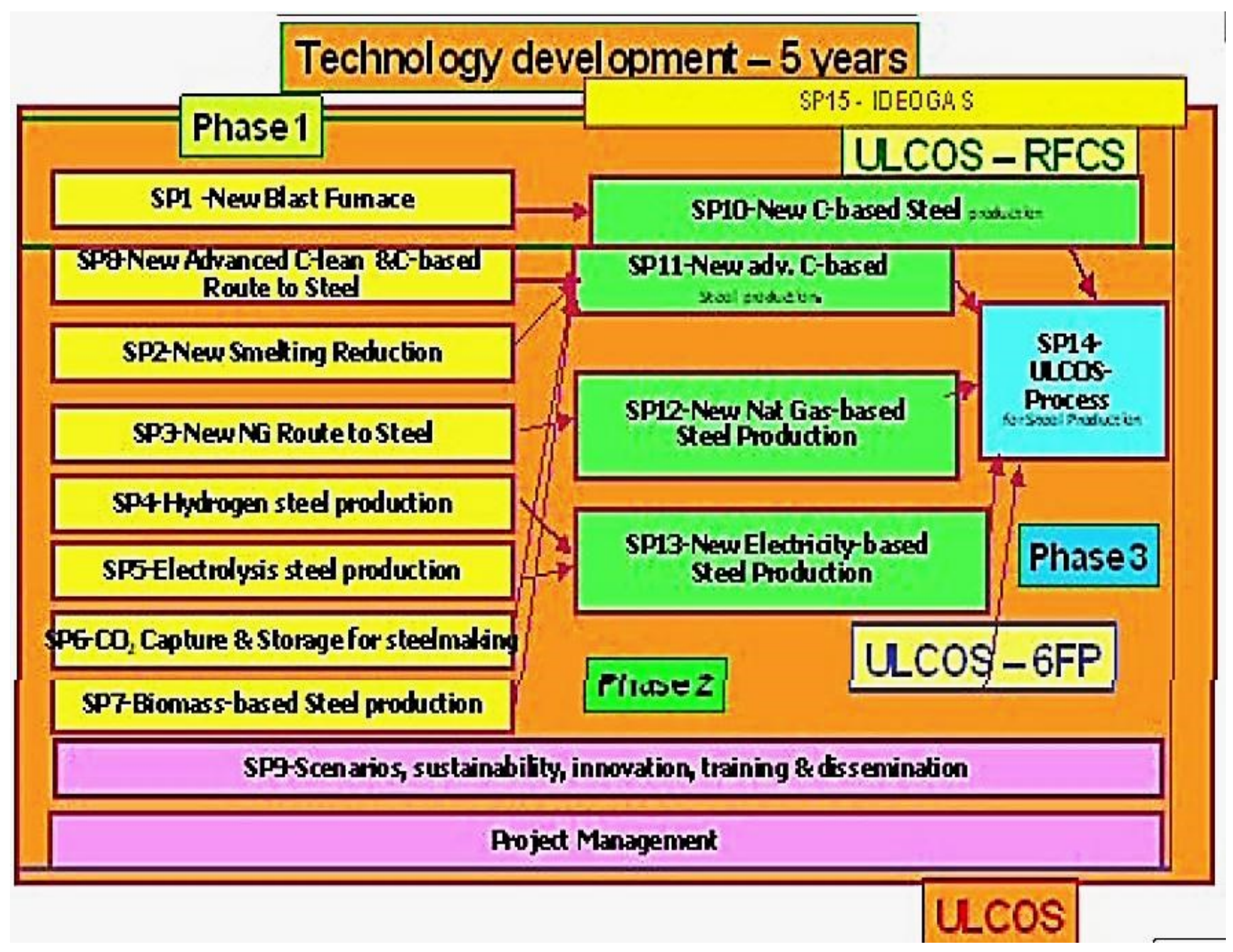

Fig. 1. ULCOS Program structure (Ulcos, 2013).

The Kyoto protocol was signed in 1997 as a mark of global approach to the issues of greenhouse gas and how to mitigate it. Implementation of these agreements includes taking legal actions on member countries who fail to abide by the agreement but not all steel producing countries accepted including USA and Australia in the decline list (Peter, 2007). 
Considering the bulk quantity of emission urgent measures were put in place to tackle the problem. Some commonly adopted measures include $\mathrm{CO}_{2}$ sequestration, Mineral carbonation and the use of slag sequestration which is economical as it does not involve transporting $\mathrm{CO}_{2}$ through pipes to reservoir sites. About $0.25 \mathrm{~kg}$ of $\mathrm{CO}_{2}$ can be sequestered in $1 \mathrm{~kg}$ of slag (Xu and Da-qianq, 2010). Other possible measures to cut down $\mathrm{CO}_{2}$ is to reduce the use of fossil fuels for example using natural gas instead of coal and a forestation to help reduce $\mathrm{CO}_{2}$ concentration through photosynthesis by the plants (Farla et al, 2013).

The ultra low $\mathrm{CO}_{2}$ steelmaking programme (ULCOS) was established in 2002 by a number of EU member countries and organizations with the mandate to find ways out on how to cut down $\mathrm{CO}_{2}$ emission by at least $50 \%$ of the present volume of emission. A lot of programs are put in place by ULCOS with a view to possible reduction $\mathrm{CO}_{2}$ by improving on or modifying the process routes in steelmaking. ULCOS for the purpose of efficiency divided its program into subprojects with each group looking at certain problem area (Xu Da-qianq, 2010; Ulcos, 2013).

\section{RAW MATERIALS GOING INTO FURNACE}

What materials go in to the furnace determines the amount of greenhouse emission. Today coal reserves are limited so there is the need for new technologies that dispense coking and sintering in the production processes. Biomass can replace coal used in both BF and DRI it is renewable and readily available, $\mathrm{CO}_{2}$ emission from biomass does not add to greenhouse problems as it is just similar to carbon fixation by plants.

The calorific value of biomass is less than that of coal but it is sufficient to effect energy conversion. Biomass is a potential reducing agent of iron ores and the weight required to reduce ore varies with the type of ore used and the purity of the biomass (Vladimir, 2006).

\section{3. $\mathrm{CO}_{2}$ EMISSIONS FROM IRON AND STEEL PRODUCTION}

As the demand for iron and steel products has increased in recent years and consequently this involves the use of large amount of energy, equivalent to $5 \%$ of the primary energy use in EU and around the globe. The volume of $\mathrm{CO}_{2}$ emitted per ton of steel is approximately $2200 \mathrm{~kg}$ (Xu and Da-qianq, 2010). The emission results from the use of fossil fuels as a source of energy and carbon as reducing agent (Ulcos, 2013). While energy required for production depends on process route (Katja and Jayant, 1998; Peter, 2007). For example the energy utilized in Blast furnace/Basic oxygen furnace is around 17.4 to 18.6 $\mathrm{GJ} / \mathrm{tcs}$ and that for Electric arc furnace route is 8.3-9.8 GJ/tcs. (Peter, 2007).

The $\mathrm{CO}_{2}$ emission depends on the amount of energy consumed in the different process routes, for $\mathrm{BF} / \mathrm{BOF}$ is about 1.8 tons $\mathrm{CO}_{2} /$ ts and for $\mathrm{EAF}$ is 0.5 tons $\mathrm{CO}_{2} /$ ts, and more $\mathrm{CO}_{2}$ is emitted from $\mathrm{BF} / \mathrm{BOF}$ route than $\mathrm{EAF}$ because more than $60 \%$ of steel production is from $\mathrm{BF} / \mathrm{BOF}$ route (Vladimir, 2006). 

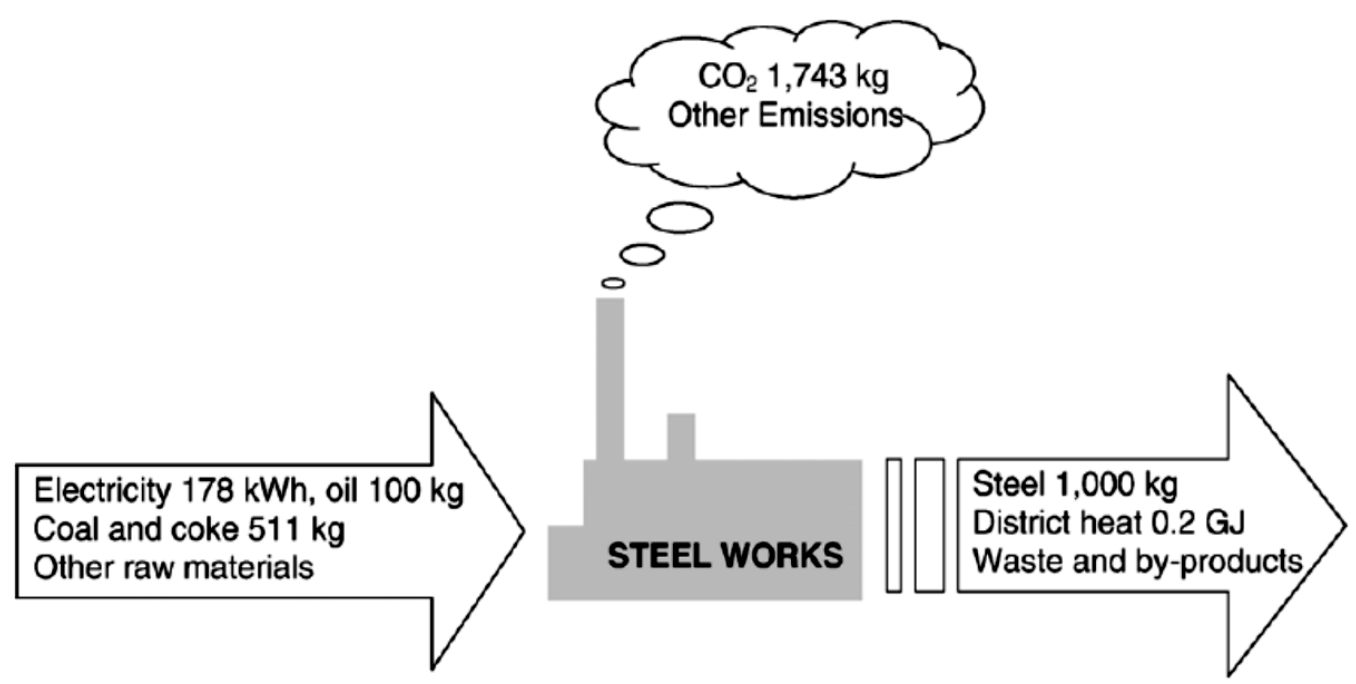

- Example of energy and emission flows to produce 1 ton steel with the BF/BOF process at Raahe steel works.

Fig. 2. (Ulcos, 2013.)

The life cycle of steel gives the life pattern of the steel from manufacturing (raw materials to steel products) through fabrication and application of the product to finally recycling. It is very important to consider ways of processing steel with little energy input and low greenhouse gas emission

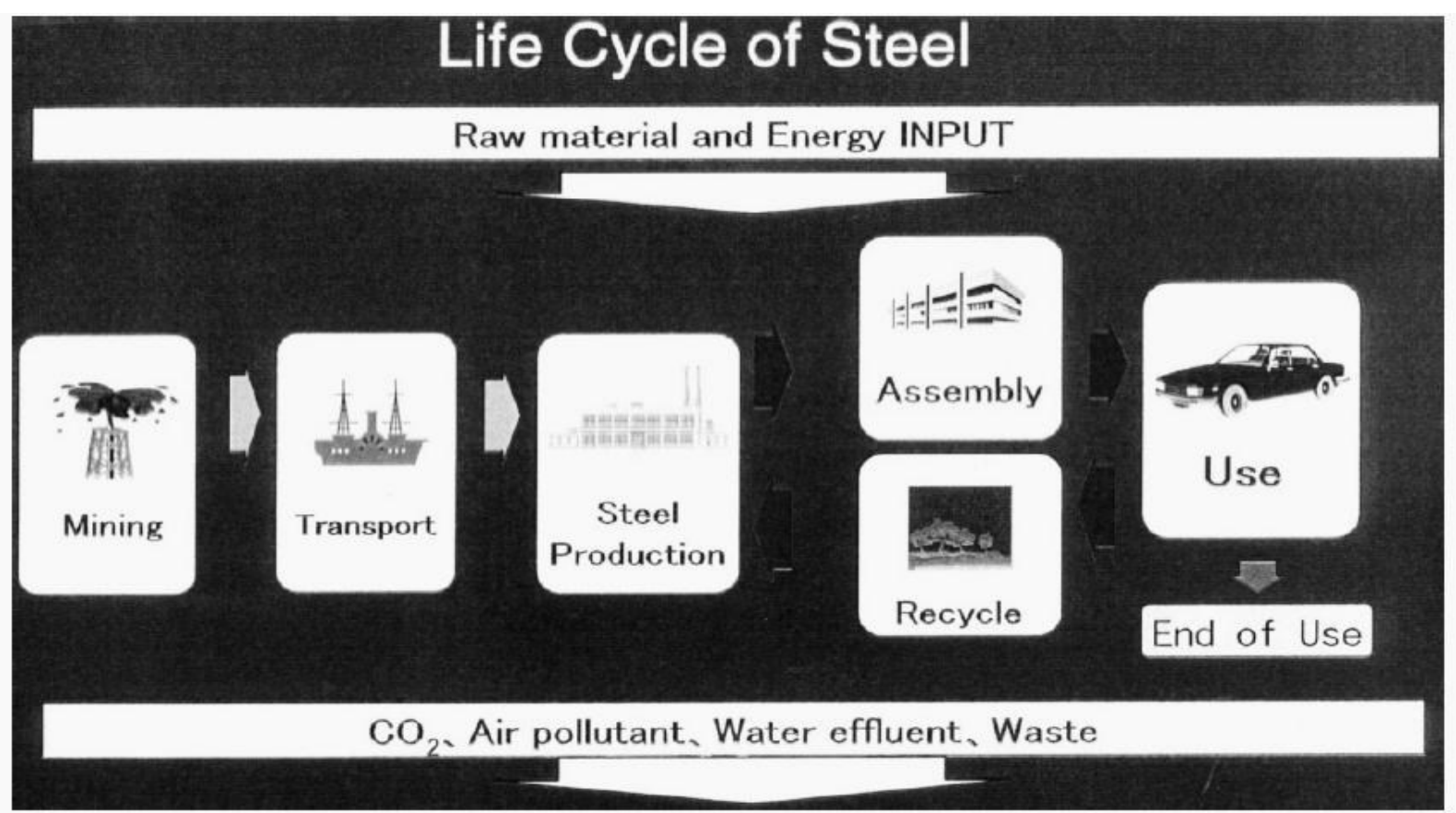

Fig. 3. Life cycle of steel (Kawai, 2001). 
The efficiency of the primary production steps matters in $\mathrm{CO}_{2}$ reduction, what is meant by efficiency here may include reduced electricity and fuel consumption. In BF emission can be cut down by substituting coal with hydrogen containing substances like natural gas and steam and when hydrogen is used to reduce iron ore, the by product is steam and not $\mathrm{CO}_{2}$. ULCOS proposed the following to curtail $\mathrm{CO}_{2}$ emission problems (USEPA, 2010).

\section{4. $\mathrm{CO}_{2}$ RECOVERY FROM IRON AND STEEL PRODUCTION}

Nearly $70 \%$ of carbon that goes into the blast furnace is emitted as gas this explains the need for recovery. Many recovery techniques are available, the common one is chemical absorption which is preferably used to recover $\mathrm{CO}_{2}$ reason for choosing it is because $\mathrm{CO}_{2}$ has a low partial pressure. $\mathrm{CO}_{2}$ recovery is an important step towards reducing greenhouse gas. Hoogovens group is a very large steel industry in Netherland that recovers large amount of $\mathrm{CO}_{2}$ emission is recovered and utilized while some quantity being sold out to regional power stations. The quantity purchased by the regional power station is estimated to be 3.6 Mtons of $\mathrm{CO}_{2}$ in 1986 alone. More than $75 \%$ of steel industries in Netherlands have incorporated gas recovery units (Farla et al, 2013).

\section{THE CAPTURE AND STORAGE OF $\mathrm{CO}_{2}$}

$\mathrm{CO}_{2}$ capture and storage is one of the measures to control greenhouse gas problem. The gas is captured and stored in special reservoir especially deep aquifers (Xu and Da-qianq, 2010). Since the gas is in a mixed form containing $20 \% \mathrm{CO}_{2}, 23 \% \mathrm{CO}, 3 \% \mathrm{H}_{2}$, and $52 \%$ $\mathrm{N}_{2}$ so it has to be separated and captured and then pressurized and transported before finally stored in the reservoirs (Xu and Da-qianq, 2010; USEPA, 2010). This practice is acceptable in recent years and it can be done in one of the following processes (i) the liquid chemical absorption and ii) the physical absorption and iii) the solid adsorption (Xu and Da-qianq, 2010). The $\mathrm{CO}_{2}$ is well protected by the rocks covering the oil and gas so cannot escape to the free surface. The oil and gas reservoir is a potential store with capacity of about 140Gton which is more than 20 times the annual global emission of carbon put at 7 Gtons. Another reservoir is the deep ocean (ULCOS, 2013)., with storage capacity of about $10^{19}$ tons although this is a capital intensive process as it involves laying pipes to reach the deep ocean. This type of storage is commonly known as carbon dioxide sequestration. Mineralization is also a $\mathrm{CO}_{2}$ capture process where reaction between the $\mathrm{CO}_{2}$ and magnesium based rocks converts $\mathrm{CO}_{2}$ into stable carbonates. Slag in steel production is proposed to be used as reactant to absorb $\mathrm{CO}_{2}$ as follows $\frac{1}{2} \mathrm{CaSio}_{4}+\mathrm{CO}_{2} \rightarrow \mathrm{CaCO}_{3}+\frac{1}{2} \mathrm{SiO}_{2}$ (Xu and Da-qianq, 2010).

\section{MODELLING OF INTEGRATED PLANTS}

In this modeling gas produced internally are used to generate electricity. The gas is obtained from the oven furnace and the converter, although not all the gas produced are used for the electricity generation some are used for heating purposes. 


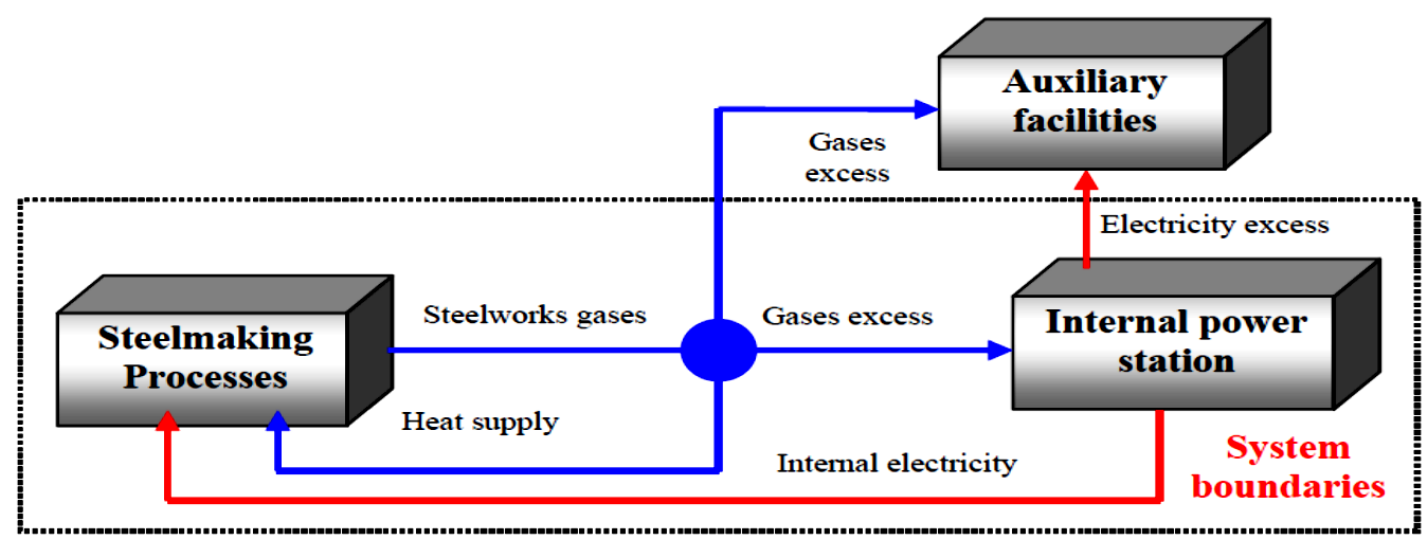

Fig. 4. Internal electricity generation (Losif et al 2013).

The excess gas can be used as energy source for auxiliary units such as steam and lime production (Losif et al, 2013).

\section{DIRECT REDUCTION PROCESS}

The direct reduction process is capable of cutting $\mathrm{CO}_{2}$ by $20 \%$ through avoiding some practices common in the Blast furnace route ( $\mathrm{Xu}$ and Da-qianq, 2010). This process also produces DRI using shaft furnace, $\mathrm{CO}_{2}$ from this process are captured and off gas recycled (ULCOS, 2013).

\section{SMELTING REDUCTION PROCESS}

This process basically involves the use of molten metal to reduce iron oxide and to gasify carbonic materials. Environmental emissions are reduced in this process because coking coal are not used and dispensing sinter plants by using lump ore. A typical type of these processes includes the Corex, Finex and the HIsmelt, the Corex is developed by Siemens (Xu and Da-qianq, 2010). In this process pure oxygen is used and off gas can readily be stored (ULCOS, 2013).

Top Gas Recycled (TGR -BLAST FURNACE):

In top gas recycled blast furnace process $\mathrm{CO}_{2}$ emitted is stored and the remaining gas sent back into the furnace through the base and act as reducing agent (ULCOS, 2013).

\section{CONCLUSIONS}

Many countries have taken different measures to deal with the issue of global warming resulting from their industrial emissions, although this is a broader and more general approach to the problem as we are only concerned with emissions from iron and steel industries and specific steps taken by such industries to cut down greenhouse gas. In fact the steel industries has been confronted with the issue of global warming and most countries involve in iron and steel production have passed serious internal legislations and are signatories to international policies to try mitigate the problem. 
The setting up of ULCOS as a body responsible for achieving the greenhouse gas cut down has put in place a lot plans to be implemented by the steel industries. Carbon capture and storage is seen as the most urgent and more effective way to control $\mathrm{CO}_{2}$ emission despite problems of implementation in large commercial scale. Secondly the possibility of using steel slag for $\mathrm{CO}_{2}$ sequestration is also receiving attention where the basicity and acidity characteristics of the slag play an important role. Here sequestration is achieved through interaction between the $\mathrm{CO}_{2}$ and cations. Thirdly, $\mathrm{CO}_{2}$ recovery is also one way of reducing greenhouse emission, majority of $\mathrm{CO}_{2}$ emission take place in the Blast furnace so recovery from this point is necessary though is capital intensive but it is a wise investment.

\section{References}

[1] Bonenfant D., Kharoune L., Souve S., Hausler R., Niquette P., Mimeault M., Kharoune M., International Journal of Greenhouse Gas Control 3(1) (2009) 20-28.

[2] Chang Y. F., Lewis C., Lin S. J., Energy Policy 36 (2008) 2471-2480.

[3] Farla J. C. M., Hendriks C. A., Blok K., $\mathrm{CO}_{2}$ Recovery from Industrial processes. Retrieved June 21, 2013 from www.springerlink.com/index/u7075275w920x688.pdf

[4] Kawai J., Materials \& Design 22(2) (2001) 111-122.

[5] Katja S. Jayant S. (1998). India's Iron and Steel Industry. Retrieved June 20, 2013 from http://ies.lbl.gov/iespubs/41844.pdf

[6] Katja S., Sand R. D., Energy Economics 29(4) (2007) 799-825.

[7] Losif A. M., Birat J. P., Mirguax O., Ablitzer D., Reduction of $\mathrm{CO}_{2}$ Emissions in the Steel Industry based on LCA Methodology. Retrieved june 20, 2013 from www.ulcos.org/en/docs/Ref33\%20-\%20TMS_CO ${ }_{2}$ correct_1.pdf

[8] Lonescu A., Candau Y., Environmental Modelling \& Software 22(9) (2007) 1362-1371.

[9] Peter L., Ecological Economics 63(4) (2007) 799-806.

[10] ULCOS Program Addressing Climate Change Challenge. Retrieved July 10, 2013 www.ulcos.org/en/docs/Ref28\%20-\%20ISIJ_157_H0053.pdf

[11] U.S. Environmental Protection Agency 2010. Available and Emerging Technologies for Reducing Greenhouse Gas Emissions from Iron and Steel Industries. Retrieved June 22, 2013 www.epa.gov/nsr/ghgdocs/ironsteel.pdf

[12] Vladimir S., Renewable Energy 31 (2006) 1892-1905.

[13] Xu C., Da-qiang C., Journal of Iron and Steel Research, International 17(3) (2010) 1-7. 